\title{
Jacob, la inspiració, Joan Vinyoli
}

\author{
[Jacob, the inspiration, Joan Vinyoli]
}

\author{
JoAn Requesens i PiQuer \\ Reial Acadèmia de Bones Lletres de Barcelona \\ jreques.piq@gmail.com
}

Resum: El patriarca bíblic Jacob és el referent objectiu amb el qual el poeta Joan Vinyoli construeix el poema «Nit d'àngel». El seu estudi en el context del poemari on és inclòs, $E l$ Callat, em porta a veure'l com una exposició, diguem, del que per a ell és la paraula "inspiració". Diria que Vinyoli, feta l'anàlisi del poema i una possible interpretació, ens hi mostra quin és l'esforç d'accés a la pròpia i més fonda interioritat, la qual retorna a l'exterior amb el treball poètic, és a dir, en la construcció que ell anomena «els cants». L'experiència de Jacob d'haver lluitat amb un àngel, doncs, com a imatge reflexa de la descoberta de la intimitat i, simultàniament, de quin és el sentit de la seva vida de poeta.

PARAUles ClaU: Jacob, inspiració, interioritat, símbol, transcendència, natura.

AвSTRACT: The biblical patriarch Jacob is the objective reference with which the poet Joan Vinyoli constructs the poem «Nit d'àngel». His study in the context of the book of poems in which is included, El Callat, makes me see it as an exhibition, let us say, of what for him is the word "inspiration". I would say that Vinyoli, once the analysis of the poem and a possible interpretation have been made, shows us what the effort is to access one's own deepest interiority, which returns to the exterior with the poetic work, that is, in the construction of the one he names "els cants". Jacob's experience of having struggled with an angel, then, as a reflection of the discovery of intimacy and, simultaneously, of what is the meaning of his life as a poet.

KEY WORDS: Jacob, inspiration, interiority, symbol, significance, nature.

Recepció: IO/OI/2020. Acceptació: 26/0I/2020. Publicació: 27/07/2020

REVISTA VALENCIANA DE FILOLOGIA / IV (2020) p. 223-250/ISSN 0556-705X DOI IO.28939/RVF.V4.I37 
Un poema per a ser llegit, pot ser rellegit. Un poema per a ser pensat, no tant en la seva estructura estròfica ni tal volta en la combinació de versos de síl·labes parelles, hexasílllabs, octosílllabs i un decasílllab, com en el seu contingut i significació. Aquest és, ben mirat, un exercici d'entreteniment que m'ha plagut i que proposo, gosat, al lector perquè conegui el poema, el retrobi i, si li plau, que llegeixi les meves pàgines, ratlles una sota l'altra sense cap pretensió, cap ni una. O potser sí.

Pretendre que la meva lectura s'adigui tant com pugui amb unes paraules tretes d'un llibre que si no ho és poc li falta per a ésser un clàssic entre els estudiosos de la literatura. És l'obra de Northrop Frye, The Great Code. The Bible and Literature. En tinc la versió francesa i d'aquesta recupero un pensament del capítol que tracta de les imatges bíbliques, diguem-ne la imatgeria de la naturalesa repartida en jardins, pastors i ramats, muntanyes i monstres marins, com també en personatges que esdevenen simbòlics o prototípics de virtuts i de vicis, etc. En aquest context, afirma que la imatgeria, en el seu conjunt, constitueix una part del que ell anomena el món apocalíptic, el món ideal —quan se'l mira des d'un determinat punt de vista- que envolta la imaginació creadora dels homes, que l'energia humana assaja de realitzar i que la Bíblia presenta com una forma de «revelació» (i a continuació ja no tradueixo per ser més fidel al text imprès del meu davant): «la vision, le modèle, le plan qui donne une orientation aux énergies de l'homme» (Frye 1984: 201).El poema és el central —el quart de vuit- de la darrera secció que porta el mateix títol que el general del llibre, El Callat i el segueix el poema amb el mateix nom —insistència significativa?-, nou decasíllabs.

Nit D’ÀngEL

He lluitat amb un àngel

d'inusitat ardor

—ell gran i fort, jo temerari-,

vingut a mi perquè participés

d'allò més alt que salva.

REVISTA VALENCIANA DE FILOLOGIA / IV (2020) p. 223-250

JOAN REQUESENS I PIQUER

Jacob, la inspiració, Joan Vinyoli / 224 
Tens com la nit, amb meravella

i espant, entre les seves

mans debatent-me, quin misteri

naixia en mi, que m'igualava

com a la nit, sobrepassant-me?

Quasi vençut, ell em cedia

part del seu foc, jo veia

l'escala de la llum,

per on els cants davallen

al solitari cor.

Fem la trampa, si més no inicialment, d'una interpretació descontextualitzada, els versos sols i la seva intel-lecció espontània. La veu poètica confessa haver lluitat amb algú que, foraster, li és vingut amb una violència que ell no ha defugit, temeràriament, perquè el vol fer participant d'una realitat superior que és salvadora. De nit, diguem en la solitud, en la fosca del més íntim d'un mateix que el trasbalsava fora mida, queia gairebé vençut, però se li havia encomanat part de l'ardor del seu contrincant i veia com al seu solitari interior arribaven els cants. La poesia?

El personatge, la fosca i la lluita són els tres elements inicials que dirigeixen el lector a una font inspiradora, si més no, a un text que serveix al poeta per bastir la trama externa dels versos. En la Bíblia, llibre del Gènesi, Jacob lluita amb un àngel (32: 23-32). La narració conta que, estant sol, era ja de nit, se li presentà un desconegut - literalment un home o algú —; s'hi barallà fins a trenc d'alba; rebé un cop en una cuixa —al nervi femoral precisa la interpretació des d'antic-; li demanà el seu nom i no rebé resposta. A la primera claror, coix, amb un altre nom que li havia dictat el lluitador anònim, donà al lloc de la brega nocturna el nom de Panuel, que significa 'he vist Déu cara a cara i n'he sortit amb vida!'. Són els fets d'una nit que Jacob, ara Israel, pot afegir al somni d'una nit precedent, quan va veure una escala que de la terra s'enfilava al cel per on pujaven i baixaven àngels, més la veu d'Elohim o El, el déu més misteriós com cap déu dels altres pobles d'aleshores, assegurant-li que era al seu costat i mai

REVISTA VALENCIANA DE FILOLOGIA / IV (2020) p. 223-250

JOAN REQUESENS I PIQUER

Jacob, la inspiració, Joan Vinyoli / 225 
no l'abandonaria (Gn 28:10-15). Prescindim, ara, de la vellíssima tradició que explicava el significat del topònim Panuel, és a dir: peni'el ('cara de déu') i així donar raó del canvi de nom del patriarca i per fer entendre la importància de la seva descendència perquè Jacob havia intuït qui era el lluitador i li demanà que el beneís, com així fou, a més de ferir-lo a la cuixa. Sí que hem de tenir present que la versió llatina, tot i parlar de vir ('home'), el qui lluita amb Jacob, la presentació del text l'ha intitulada tradicionalment com la tinguda cum angelo ('amb un àngel') a partir del text del profeta Osees que si bé en la redacció original parla de lluita amb Déu i amb un àngel, la Vulgata la redueix a àngel (Os 12:3-4). ${ }^{1}$

Per sota del, diguem-ne, tòpic literari, tret aquí de la Bíblia, hi ha la significació, al centre de la qual dues paraules en perfilen l'abast. Les escrites, d'entrada en llatí, tremendum et fascinans, a la segona estrofa, 'meravella i espant'; per aquestes emergeix el record del clàssic concepte en l'estudi de la fenomenologia de les religions, del fet religiós en si mateix en l'obra de Rudolf Otto, Das Heilige ('Allò sagrat'). Una tercera paraula, mysterium ('misteri') en la mateixa estrofa. Mysterium tremendum et fascinans que "naixia en mi [...] sobrepassant-me?», es pregunta el poeta, «tens [...] entre les seves mans debatent-me». La significació de tres paraules en aquest marc religiós o, diguem-ho prestament, metasensorial —el qualificarà de somni en la darrera estrofa, no pas d'acte real. Una significació que expressa el voler d'algú, amb la potència d'un foc el qual força el poeta a participar «d'allò més alt que salva». Què entendrem darrere d'aquesta paraula? Penso que molt senzillament allò que també es desprèn de la narració bíblica: el sentit de la vida, el del propi viure com a patriarca, pare gran i primer d'un poble, el d'Israel; el sentit de fer versos, l'ofici de poeta justificador del propi viure, "allò més alt», la raó última. Això és el que salva: allò que dona sentit en fer el que es fa. I el poeta de «Nit d'àngel» rep la benedicció, com Jacob, «ell em cedia part del seu foc». Així, «quasi vençut» — podem entendre la mesura humana amb aquesta afirmació? - el poeta veu,

1 «[...] Et in fortidudine sua directus est cum angelo. Et invaluit ad angelum, et confortatus est...»; però la versió original fa: «[...] i, quan va ser home, va lluitar amb Déu, lluità amb un àngel i el va vèncer...» (Os 12:3-4).

REVISTA VALENCIANA DE FILOLOGIA / IV (2020) p. 223-250

JOAN REQUESENS I PIQUER

Jacob, la inspiració, Joan Vinyoli / 226 
com el patriarca, «l'escala de la llum», però no hi davallen àngels, sinó la Poesia, així amb majúscula, síntesi dels «cants». Davallen, Ella davalla «al solitari cor», a l'íntima profunditat que el consagra, l'investeix Poeta.

Què diu, tanmateix, una lectura contextualitzada? Aquest poema forma part del llibre El Callat editat el 1956. Porta un pròleg signat el 25 d'octubre de 1955, és a dir, un any abans. Un grapat de mesos que separen la seva redacció d'una crisi religiosa que el portà a un allunyament definitiu de l'Església catòlica. ${ }^{2} \mathrm{Si}$, doncs, per coneixements religiosos l'anècdota bíblica del poema és justificable, resta el salt per damunt del verset 29 , en què se li canvia el nom a Jacob «perquè has lluitat amb Déu», i el verset 31 on, ja Israel, confessa haver vist Déu i no morir. Salta per sobre del text per només deixar present un pronom, «ell» al vers 11, i una donació, un «foc». Aleshores el poeta es troba posseïdor d'una nova mirada, la que li permet veure què descendeix sobre ell, els cants. Tal volta el poema anunciava ja la situació de conflicte interior del poeta -i el Déu dels versets resta difuminat en el senzill pronom ell. No importa, però. Descartem-ho. Sí que cal tenir en compte, per contra, les afirmacions que l'estudiós de la poètica vinyoliana, Ferran Carbó, escriu fundadament. El poema vinyolià —en sentit genèric—, és a dir, cadascun dels poemes amb els temes diferents i estructures retòriques diverses, esdevé «una apel-lació insistent al no-res metafísic, a les fonts primigènies de l'existència humana $i$, en darrer terme, la recerca de la identitat individual a través de la poesia i de la paraula» (Carbó 2003: 20). Rellegim les paraules del mateix poeta. Són de la carta pròleg a Perillosa riba de Josep M. Fulquet del 1976:

Deia Riba que la poesia se li plantejava com una «experiència, com a mètode de pensament i de coneixement sobre si mateix i sobre el món», i

2 Ell mateix en dona les suficients clarícies en una epístola a Lluís Busquets i Grabulosa el 1982, que, de fet, reculen al 1932 quan la coneixença d'Isabel Abelló i Soler —el 1940 va traduir amb el seu marit Tomàs Lamarca, Poesías de Robert Burns, una bandera de presentació, sigui dit de passada, remarcable- «em va convertir de veritat i profundament a la vida interior»; sense deixar una segona memòria per qui també tingué «importància en la meva joventut, Tomàs Lamarca» (Vinyoli 2001: 500-501 ), i restaven enrere vint-i-dos anys d'educació jesuítica i vida fervorosa.

REVISTA VALENCIANA DE FILOLOGIA / IV (2020) p. $223-250$

JOAN REQUESENS I PIQUER

Jacob, la inspiració, Joan Vinyoli / 227 
precisava més el sentit d'aquesta experiència dient que «tota poesia prové d'una il·luminació espasmòdica o tranquil·la, però que no pertany ben bé a la consciència, sobre una realitat íntima que no ens importa tant de considerar com de veure» (Carbó 2003: 29-30; Vinyoli 2001: 495-496).

Unes altres, aquestes en carta a l'esmentat en una nota Lluís Busquets i Grabulosa, diuen:

Les paraules serveixen per a fins utilitaris i per a fins estètics. Les paraules del poeta només en segon terme han de significar o designar. Han d' «evocar» sobretot. Quan algú, fins el més senzill, diu que troba poètica una cosa, poso per cas l'aurora o una fageda encesa a la tardor o una brunyida posta d'hivern, vol significar un estat d'ànim que allò que veu o troba "poètic» li fa pensar o "sentir» una "altra cosa» que podríem dir-ne «permanència feliç» en lloc de caducitat o fugacitat. Tal vegada el sentit últim d'aquesta «permanència feliç» seria el «real poètic» (Vinyoli 2001: 502-503).

Evocar per «sentir» una «altra cosa» és, entenc, el que hi ha darrere el poema presentat aquí. Recuperar una història patriarcal bíblica per evocar, el poeta, i per sentir, el lector, una realitat de més enllà. D’un més enllà perquè Vinyoli capta que la paraula primera d'un poema li ve de fora — si més no inicialment - com de moltes maneres semblants ho confessen altres poetes, de Joan Maragall a Josep Carner o de Friedrich Hölderlin a Paul Valéry. ${ }^{3}$ Vinyoli es considera deutor de Rainer M. Rilke, com a il-luminador del seu pressentir: «el meu encontre amb Rilke es degué a un atzar [...] la traducció del famós fragment dels Quaderns de Malte Laurids Brigge on afirma, resumint, que la poesia «no és cosa de sentiments, sinó d'experiències» (Vinyoli 2001: 501). Aquí volia arribar. Vinyoli fa seu Rilke i d'alguna manera és la confessió d'una experiència el que hi ha sota el «solitari cor» (v. 15) del «quasi vençut» (v. 11), no pas cap sentiment.

3 En aquest ordre recordarem «la paraula viva", una «intrusa», una veu sagrada que li parlava, els déus que regalen el primer vers, (veg. Carbó 2003: 25).

REVISTA VALENCIANA DE FILOLOGIA / IV (2020) p. 223-250

JOAN REQUESENS I PIQUER

Jacob, la inspiració, Joan Vinyoli / 228 
Resta només en el poema, una petitesa, entenc, que pot passar desapercebuda sota l'anècdota bíblica. El text del Gènesi té tota la traça de contar la història d'un fet inesperat: Jacob ha restat sol i se li presenta un home-algú en acció de brega. El poeta, per contra, no ens diu que la iniciativa de la lluita ha estat seva? El vers inicial és pura anunciació en passat, neutre en podríem dir, «he lluitat». El tercer anuncia una descripció doble, física per al contrincant, psíquica per a ell: «gran i fort» enfront de "temerari», és a dir, dos punts de visió diferents perquè el com és l'altre, parteix d'una objectivitat, mentre que la seva ho fa des de la subjectivitat, com si diguéssim; l'un empès per la circumstància mentre que ell ho és per la voluntat. Ara bé, una voluntat que es coneix i, per tant, no dissimula la gosadia d'haver decidit, puix que es qualifica de «temerari», de qui es llança al perill sense reflexionar, audaciosament, fins tal volta sense motiu (tot repetint quasi exactament el diccionari). Cert que el quart vers pot semblar contradir aquestes ratlles, «vingut a mi», això és, com en el relat bíblic se li presenta. Sí, cert, arriba, se li presenta amb una intenció expressa i explícita. Però l'afirmació d'un «jo temerari» fa que realment la voluntat del poeta hagi decidit d'acceptar l'embat. Si hagués mesurat les forces... la temeritat mou la voluntat a l'acceptació de la lluita. ${ }^{4}$

L'aventura transformadora del vianant Jacob quan retornava al seu país. Un poeta i l'aventura semblant sense moure's de casa. Aquell esdevé patriarca amb el nom canviat. Aquest, «[...] quin misteri / naixia en mi [...]?» La inspiració? «[...] jo veia / l'escala de la llum / per on els cants davallen».

4 No tinc cap raó ens aquests moments per a suposar que els versos de Vinyoli siguin, d'alguna faiçó, una mirada contraposada a la de Carles Riba en el poema que també pren el tema de la lluita nocturna de Jacob. És el poema 24 del segon llibre de les Estances. «[...] Hem lluitat braç a braç / vencedor ell, ha pres ell ma tristesa", versos 11-12 amb total oposició: aquí és l'àngel qui pren mentre que en el poema de Vinyoli és qui li dona del seu foc; per això, aquell acaba «[...] Si ara vull Déu, / sóc sol — titànic laberint, nou dia!», final allunyat del tot respecte de «Nit d'àngel». Només val afegir-hi l'observació de Jordi Pinell en fer notar que el primer poema d'aquest segon llibre de les Estances comença justament així: «Silenci, àngel potent, / missatger entre Déu i el nostre pensament», la funció clàssica atribuïda als àngels del Déu judeocristià que (aquí hi ha el matís ribià i no tradicional) fa de pont al pensament, no al cor o a l'ànima com a receptacle de dons divins (veg. Pinell i Pons 1986: 52-53)).

REVISTA VALENCIANA DE FILOLOGIA / IV (2020) p. $223-250$

JOAN REQUESENS I PIQUER

Jacob, la inspiració, Joan Vinyoli / 229 
Joan Vinyoli, en el pròleg que precedeix El Callat, escriu frases com aquestes: «Creia [...] que hi ha un cant líric més profund [...] que el contacte amb les profunditats [d'un mateix] predisposa al silenci i que sols [...] en pura contemplació, es resol en cant. No pretén l'autor tenir raó ni suggerir res de místic» (Vinyoli 2001: 82); i en el penúltim paràgraf, parlant directament d'aquest recull —no en general com en les pàgines precedents-, escriu:

[...] que si per El Callat podria pensar-se en una poesia predominantment dirigida cap al numinós, l'esperit que batega en molts poemes del llibre sembla més aviat decantat a la terra. Però, tanmateix, creu l'autor que sols partint de "El Callat", sols de retorn de "El Callat", sols havent sentit la crida del "Gall" i l'enyorança de "La roca", sols per "Camí" on "en la set del qui cerca neix profunda la deu", per "El boscater" perdut en la closa nit on "Orfeu" és "esperança i moviment cap a la llum" i on cal arriscar-se al difícil combat amb l’àngel, arribar a la clara altura de "Diumenge" i fer la lloança i fins l'exaltació de les realitats terrenes: siguin flors o fruits, muntanyes o ponents, jardins o infants que en llur simple gràcia caminen lliurement cap al "Delitós paratge" "d'aigües aturades" on "El Callat" fa sentir la seva "quasi-veu" (Vinyoli 2001: 84).

El lector ja haurà capit tot d'una que Vinyoli remet un cop i un altre a diversos poemes del recull i fins reprodueix alguns versos per tal de fer-se entendre en una direcció més que no pas en una altra. Uns poemes dels quals qui no n'és l'autor n'extreu, ara, altres versos amb la gosadia de posar-los al costat dels d'aquest pròleg per certificar la paraula de l'autor i, si pot, cercar més enllà o, per un altre vial, nous sentits. El poemari sembla, pot pensar-se, anar vers una direcció, la del sagrat, i, per contra, sembla decantat a la terrenalitat. Ho afirma l'autor. Al lector, altrament, davant de l'aplec verbal poder i semblar, li correspon d'acollir les dues direccions interpretatives, enfilar la primera o bé acompanyar el poeta en la segona, o també simultàniament les dues? El Callat, un nom escrit sempre amb majúscula i amb díctic determinat obliga a fer-se

REVISTA VALENCIANA DE FILOLOGIA / IV (2020) p. 223-250

JOAN REQUESENS I PIQUER

Jacob, la inspiració, Joan Vinyoli / 230 
preguntes considerant, d'entrada, que és una nominació simbòlica. De què? De qui? El poema «Nit d’àngel» és seguit justament del titulat «El Callat» i darrere «Diumenge». Llegim:

\section{El Callat}

M'endinso pel teu àmbit, primavera del càntic, una veu entre les veus ofertes al Callat, que per les coses m'envia el seu alè. Quina avinguda secreta tot de sobte m'ha portat a delitós paratge? Selva muda, com els infants camino, lliure, lliure, sentint la veu que del Callat arriba a mi, bevent el seu somriure.

Algú podria dir que el secret del poema s'amaga en la sintaxi i no s'erraria gaire, penso. Principia amb un vers en primera persona, és a dir, la veu del poeta parlant, adreçant-se a la "primavera del càntic» que tot apunta que resta especificada com una realitat —s'haurà de cercar quina amb més deteniment- amb les paraules següents, aquestes, «una veu entre les veus» de les diverses «ofertes al Callat» el qual, a través o per mitjà de «les coses m'envia el seu alè». Entenguem que la "primavera del càntic» és l'inici del camí que ha fet el poeta i de nou, ara, retorna a l'«àmbit» del càntic, això és, al seu viure i al seu fer poètic. És una veu oferta al Callat que envia la inspiració al poeta si inspiració l'entenem com a sinònim d'alè, un mot per no perdre'l de vista. Tres personatges, diríem: el poeta, una de les veus del fet poètic i el Callat; una veu, doncs, del fet poètic lliurada al Callat, i aquest envia el seu alè al poeta a través de les coses. Realment el trencacoll és el Callat, un què o un qui que rep una veu i ofereix un alè. Un què que pot ser la imatge o simbologia de la capacitat lingüística conformada per multiplicitat de veus, enteses com les temàtiques múltiples que poden ésser transmeses, expressió del món real, lògic o no, expressió del món imaginat coherent o incoherent, expressió de vivències o fantasies, expressió poètica. Així el Callat, al seu torn, ofereix

REVISTA VALENCIANA DE FILOLOGIA / IV (2020) p. 223-250 JOAN REQUESENS I PIQUER Jacob, la inspiració, Joan Vinyoli / $23 \mathrm{I}$ 
al poeta el seu alè, entès, diguem de moment, com la capacitat lingüística que conté l'expressió poètica, el cant. És el Callat, també, el jo profund de Joan Vinyoli, allà on és poeta en el silenci de l'inconscient, podríem dir, on només hi ha una «quasi veu» i necessita del Vinyoli de carn i ossos i amb la llengua que expliciti la profunditat, el cant. Al pròleg tenim: «quan el cant es forma així, després d'aquesta immersió en la vida profunda [...] les paraules ja no signifiquen en ell [el poeta] el mateix: ni, en tant que signes, ja no al-ludeixen a la realitat quotidiana, sinó a la que el poeta entreveu en la seva experiència profunda» (Vinyoli 2001: 84). «El Callat»: «avinguda secreta», «delitós paratge»?, «selva muda». "Nel mezzo del camin...» el poeta camina —verb en primera persona del present- «lliure, lliure com els infants». Com qui no s'adona de la mudesa de la selva que en una altra hora per a un altre fou «selva oscura». Aquí en aquest lloc i en aquesta situació anímica "sentint la quasi veu que del Callat arriba a mi». El Callat: potser és l'àngel del poema precedent que no li diu res, que, fet i fet, és només una "quasi veu» perquè en el text bíblic parla per canviar el nom de qui ha lluitat amb ell, mes amb el poeta, ni això. És un paral-lel a la veu que li diu: «perchè non sali il dilettoso monte / ch'è principio e cagion di tutta gioia?» Per què no retornes a la muntanya, fora de la selva muda on tota cosa posseeix la veu del seu esclat $i$ ofrena joia? ${ }^{5}$ «[...] les coses» - «l'esperit que batega [...] decantat a la terra». I l'autor enyora la roca:

\section{LA ROCA}

$[\ldots]$

Ai!, arbre del meu crit, que les arrels penetrin en la roca mentre creixo cap a la nit i em perdo; que la mort no pugui ja trobar-me com una herba, que em senti, roca, sempre, a les arrels. (v. 13-17)

5 Per què no veure aquí Virgili amb els versos de la Divina Comèdia del Dant?, Infern, I, 1-2; 77-78.

REVISTA VALENCIANA DE FILOLOGIA / IV (2020) p. 223-250

JOAN REQUESENS I PIQUER

Jacob, la inspiració, Joan Vinyoli / 232 
El cant li esdevé crit i s'eixampla com el brancam d'un arbre - «ja no sóc més que un arbre que s'allunya del bosc» (primer vers, l'inicial de tot el llibre!) - i el vol arrelat no pas a semblança de l'herbam, sinó amb un tenir les rels damunt la roca que, però, no l'ateny i l'enyora, restant-li «El camí», poema entre «Diumenge» $\mathrm{i}$ «El gall». Fer camí entre (aquests són els noms en els versos): areny, neu en el bosc, ombres, genolls, vent, llum, incendi, matí, planura, nit, temps, aigua, llavis, pedra, set, deu. Els qualificatius i precisions: recremat, l'areny; el matí gloriós ho és de l'incendi; de la nit sense temps ho és la planura; vera, l'aigua; el poeta s'ha trobat de "genolls entre el vent i la llum» i ha descobert que la pedra no és per als llavis o bé que per als llavis no és l'aigua vera o que per als llavis [és] la pedra o: tot ho diu el vers penúltim: «l'aigua vera no és als llavis la pedra». Fer camí $\mathrm{i}$ «en la set del qui cerca neix profunda la deu» (darrer vers). «El boscater», el poeta: «cerco la deu, pregunto / sempre a les coses» (v. 1-2): així comença; «esquerp i solitari, m’he perdut» (v. 7), «mes a vegades [...] fora camí, l'arbre de la paraula / ressec i vell —ell, el poeta?-, murmura una llegenda» (v. 22-24) i apareix un «poderós lleó» i el personatge bíblic Daniel, el profeta (v. 28-30), i aleshores:

Estranyament agafat, com pels cabells, aleshores, com per un àngel, sóc endut en màgic vol que transfigura. (v. 31-34)

Anuncien aquests quatre versos els que vindran més avall, els de «Nit d'àngel»? Si en aquest la figura d'un patriarca ha centrar la temàtica, en el poema del boscater, alter ego del poeta, és la figura d'un profeta llançat a una fossa entre lleons segons la narració bíblica, capítol 14è de la versió grega del llibre de Daniel. Secundària és la reducció dels lleons a un sol lleó com ho fa en els versos. És important, per contra, la síntesi del text bíblic en els quatre versos copiats aquí. El primer, l'estranyesa, correspon al diàleg entre el profeta Habacuc $i$ un àngel que li mana d'anar a Babilònia a portar menjar a Daniel, a la fossa dels lleons, però no en sap el camí. El segon i el tercer corresponen

REVISTA VALENCIANA DE FILOLOGIA / IV (2020) p. 223-250 JOAN REQUESENS I PIQUER Jacob, la inspiració, Joan Vinyoli / 233 
a la part narrativa central, aquesta: «L'àngel del Senyor l'agafà pels cabells, amb la força del seu alè el traslladà a Babilònia, i el deixà sobre la fossa dels lleons» (Dngr 14:36). ${ }^{6}$ El text bíblic fineix quan Habacuc crida Daniel, aquest rep el menjar i l'àngel retorna el profeta al seu país, fragment que ja no és en el poema. Els biblistes assenyalen que el vol d'Habacuc té una marcada semblança amb un passatge del llibre del profeta Ezequiel. Conta, aquest altre profeta, que estant a casa amb els ancians de Judà tingué una visió, va veure una figura semblant a un home fet de foc i llum el qual «allargà una forma de mà i m'agafà pels cabells, i l'esperit m'aixecà entre cel i terra i em dugué a Jerusalem, en visions divines...» (Ez 8:3). ${ }^{7}$ Un tros enrere s'ha apuntat la paraula inspiració si bé "com a sinònim d'“alè", un mot per no perdre'l de vista». Aquí el tenim. En llengua hebrea, esperit vol dir, originàriament, 'vent' (Ex 10:13) o 'alè de vida' (Gn 7:15 - Mt 27:50), en Ez 37:1-14 i molts altres. Cal tenir en compte, de més a més, que l'expressió «Déu és esperit» no té sentit en l'Antic Testament perquè no es parla d'Ell amb significació essencial, sinó existencial, és a dir, per les accions que fa. ${ }^{8}$ Dos profetes i el poeta que, fent un pas més, glossant, interpretant, assumint la sorpresa d'Habacuc i les visions d'Ezequiel es veu «endut en màgic vol que transfigura». Va més enllà dels textos bíblics. Si tenim present els significats primers de 'figura', això és, 'estructura', 'imatge', 'manera de ser', derivada al seu torn del verb FINGERE, 'pastar', modelar', 'donar forma', entendrem que el poeta, o Vinyoli en la fondària del seu ésser, es descobreix amb nova figura, com transportat més enllà de la primera, «com pels cabells», «com per un àngel», simples comparacions en el llenguatge per recollir la idea. Som en el poema «El boscater», previ encara a «Nit d'àngel» que ja ens l'anuncia.

A continuació, del món bíblic al món grec: "Orfeu», el cantor davallat a l'obscuritat. L'aspiració a més perquè el poeta es troba sempre en la nit i es

6 Segons les traduccions les variants lèxiques no alteren la narració en els mots que aquí ens interessen: àngel, cabells, alè i trasllat.

7 Cal repetir l'advertiment de la nota anterior.

8 Veg., per exemple, Obermayer 1979: 114-115..

REVISTA VALENCIANA DE FILOLOGIA / IV (2020) p. 223-250

JOAN REQUESENS I PIQUER

Jacob, la inspiració, Joan Vinyoli / 234 
demana si obtindrà el do del «càntic vivent» (v. 7). És el desig talment el condicional del vers i mig de Garcilaso de la Vega que fa de lema al poema, «Si de mi baxa lira / tanto pudiera el son...». ${ }^{9}$ Podem dir el Callat que, «Dret en el cor de la tenebra, / sóc esperança, moviment / cap a la llum, veu que celebra» (v. 8-10). Celebra, si ens atenem a la successió de referències del fragment del pròleg copiat, la lluita amb l'àngel com Jacob i, ja finalment ser «a la clara altura de "Diumenge" i fer la lloança i fins l'exaltació de les realitats terrestres". Una hora sentí el «Gall» i «heus-me ací en la partió de la nit i l'aurora» (v. 2) i, ja «Diumenge»

[...] dret a les escales, en el replà d'un alt silenci

$[\ldots]$

Després de molta lluita, sols després

$[\ldots]$

Després de molta lluita, sols després, per la mirada omplir-se i retenir calladament. I el gra madura als camps. (v. 8-9, 13, 16-18).

Retorno enrere, a un punt deixat entre guions quan remarcava que la «primavera del càntic» del poema «El Callat» podíem entendre-la especificada o concretada com una realitat si de veres els mots següents eren escrits com una aposició gramatical, aquests: «una veu entre les veus», una veu, per tant, com una cosa real, una més que arriba al poeta, enviada pel Callat, a través de les altres coses, "per les coses» (v. 3). Una aposició, però, especificativa només de la paraula càntic, no pas de primavera, que és el nucli del sintagma, és a dir, el càntic com una de les veus que és oferta al poeta pel Callat. I la veu esdevé allò més real que travessa de cap a cap el poemari.

9 És l'inici de la Canción VI, veg. Garcilaso de la Vega 1979: 93. L'editor, en nota i tenint present els vuit versos següents, no s'oblida pas de recordar el do musical del personatge mític.

REVISTA VALENCIANA DE FILOLOGIA / IV (2020) p. $223-250$

JOAN REQUESENS I PIQUER

Jacob, la inspiració, Joan Vinyoli / 235 


\section{La veu d'El Callat?}

Primer poema del llibre, «Algú m’ha cridat». Retornem al primer vers del llibre ja esmentat més, ara, el segon:

Ja no sóc més que un arbre que s'allunya del bosc, cridat per una veu de mar fonda.

$[\ldots]$

Però de cop s'illluminen les nits

amb paraules com flames,

torna la veu, la veu, nocturna sempre, del mar,

cridant-me sols, cridant-me.

No costa gens de prendre's literalment aquesta veu tenint present el murmuri de les ones quietes a la sorra, o el bram en el temporal marí, però també simbòlicament. El poeta, «si veritablement és poeta, al-ludeix a una altra cosa o realitat espiritual. Però de vegades el llenguatge poètic és explícitament simbòlic, i aquet és el cas de bona part dels poemes d'El Callat» (Vinyoli 2001: 83). Si El Callat és un volum de l'any 1956, simultàniament, des de l'any anterior i allargant-se fins al 1959 Vinyoli escrivia els poemes que s'editaren el 1977 en el volum Llibre d'amic. En presentar-lo escriu: «Són el correlat objectiu verbal d'un llarg procés d'interiorització. Varen significar una immersió en les aigües més profundes de la poesia i de la vida» (Vinyoli 2001: 269). L'aigua que si fins aquí l'he aportada solament amb el mar tot i ser present molt significativament en diversos poemes, l'entomo ara des de l'afirmació de l'autor: l'aigua com la manera de dir allò viu que es mou en el seu interior més íntim. Si els poemes de Llibre d'amic "són el correlat objectiu verbal», no direm pas menys del llibre El Callat amb paraules ben semblants del mateix Vinyoli al pròleg: «realitat de presència objectiva» $\mathrm{i}$ «equivalent verbal» (Vinyoli 2001: 80). Diguem-ho amb paraules de Gabriel Ferrater: «en termes estètics: en termes morals, caldria parlar de la recerca d'alguna manifestació externa de vida on ell

REVISTA VALENCIANA DE FILOLOGIA / IV (2020) p. 223-250

JOAN REQUESENS I PIQUER

Jacob, la inspiració, Joan Vinyoli / 236 
se sabés reconèixer» (Ferreter 1971: 11) . És a dir convertir en bellesa poètica — «morosament, pacientment, sense trasbals ni èxtasi» (Vinyoli 2001: 180)— una realitat, una cosa, un fet, una història vivent que per semblança, analogia, aproximació almenys, permeti al poeta de veure-s'hi a si mateix. Diguem: Jacob i la seva lluita com a correlat, la imatge reflectida, si es vol objectiva, és a dir, un text real com a text cultural (a part la historicitat i la religiositat amb què se'l pugui llegir) i l'experiència viscuda pel poeta.

En el segon poema d'El Callat el poeta es confessa "cercant només el mar, el mar» («Foc mort», v. 9) i en el quart, «Redossada en la nit» es diu a si mateix «abandonessis trofeus / de vagaroses veus» (v. 7-8). Veus de? Les que es presenten en hores de somieig com les de quietud somiades dels dos versos següents. Vindran «difuntes veus» $\mathrm{i}$ «la veu del bosc» («Sendes, camins em criden», v. 4 i 10). I en el poema «És més endins», la «veu de l'herba / secreta, veu de tot, un amb vosaltres» (v. 8-9), la unificació del poeta amb les veus de la realitat. Ja som al poema tretzè, «El boscater»: «[...] Com la terra callo, / duresa endins la veu se m'ha girat, / arrela en el profund,...» (v. 18-20) i aquí, al final d'aquest poema, la referència al profeta Daniel ja comentada i com el poeta és endut en vol pels cabells «com per un àngel». Dos poemes més i en «El riu de pedra» espera, d'entrada,

Que la roca dels ecos no conjuri veus de record, que la secreta font de l'èxtasi del vespre no m'aturi. (v. 1-3)

I dirà:

Glaçada veu, entre els morats i els ors, la veritat és la punyent resposta que ve de terra, no de vells records. (v. 16-18)

Veu del mar, veu de les coses, veus de somnis, veus de records... Si d'aquests, sembla que la veu no n'és la veritat... no: el poeta diu a la veu glaça-

REVISTA VALENCIANA DE FILOLOGIA / IV (2020) p. $223-250$ JOAN REQUESENS I PIQUER Jacob, la inspiració, Joan Vinyoli / 237 
da - sense vida?-, que la veritat és en la terra. Diria que deixa enrere les menes de veus conegudes i se'n va "fora camí de somni i pensament» (v. 35) a més enllà, «ja nu, ja cec, em llanço en el corrent» (v. 37, el darrer). La decisió és presa $\mathrm{i}$ els sis poemes següents conformen el conjunt sota el nom general «Orfeu». En els seus versos hi haurà: ombres, silenci, nit, tenebra... ja no hi ha cap «veu», només la imatge que, imaginem-ho, haurà estat suscitada i restarà en el poema. Ho diu el darrer d'aquest conjunt, el sonet

\section{ATURO LA IMATGE PURA}

Aturo la imatge pura

de les coses en un bres de silenci que murmura, quan un déu passa a través.

\section{$[\ldots]$}

mot per mot es transfigura

l'inconegut en presència.<smiles>c1ccccc1</smiles>

Fins allò que és pur instant: flor de neu, alba, rosada, duren sempre en el meu cant.

A partir d'aquest punt resten «mot per mot,...»l' '[...] incís / de la paraula tocada» (v. 7 i 9-10) que es presentarà als ulls del lector en un vers únic, sol entre dues estrofes del poema «Un amb les coses», aquest: «Paraules són misteri» (v. 11) i els sis darrers ens fan saber que el poeta s'ha dit: «[...] camina / quietament pel viarany ombrós, / a voltes fulgurant, de les paraules» (v. 15-17). Però hi ha veus que retornen, ara en una tarda on infants juguen en un jardí, tarda "plena de veus, de clares veus» $\mathrm{i}$ «m'ha cridat algú / des de la nit» («La barca», v. 1 i 5-6). Quatre poemes més i arribem a «Nit d'àngel», on no hi ha veu, ni la més breu com en el text bíblic quan li és canviat el nom de Jacob pel d'Israel, ni això.

REVISTA VALENCIANA DE FILOLOGIA / IV (2020) p. 223-250

JOAN REQUESENS I PIQUER

Jacob, la inspiració, Joan Vinyoli / 238 
No hi ha veu, però justament és quan amb els cants que davallen de «l'escala de llum», apareix la nova veu per al Callat, per al poeta, la que li és oferta en el poema següent — «El Callat», com s'ha dit— $\mathrm{i}$ ja no n'apareix cap en els tres que resten per cloure el llibre, llevat d'una, «la veu intacta» («El gall», v. 21). Sí: el poeta es veu com el bon caçador matiner, es lleva entre dues llums encara i

sent la crida en el bosc,

$[\ldots]$

i pren el camí que duu

cap a la veu intacta (v. 18, 20-21).

Veu de res, veu de ningú? Veu mai no dita, veu només foc, escala de llum? Recordem el final del poema «Diumenge» amb el qual Vinyoli arriba «a la clara altura» on «fer la lloança i fins l'exaltació de les realitats terrenes», aquest vers: «calladament. I el gra madura als camps». El silenci tanca la porta un cop finida la lluita, quan ja el poeta «mira» i «sap» (v. 10 i 12). Ell i la terra sembrada. I aquest és el final del darrer poema:

Panell tocat per l'aurora, al cim de tot de la flama, pausadament gira el gall. (v. 22-24)

El poeta pren el camí cap a la veu intacte. Ell i el gall del panell.

Serà «la veu intacta», no solament la no pronunciada quan en la lluita amb l'àngel rebé part del seu foc i els cants en el seu solitari cor? Serà el misteri que hi ha en les paraules? Serà dir quin és el «[...] port d'origen: / l'inconegut» («Redossada en la nit», v. 13-14)? Serà aquella que fa el «[...] canvi / de les coses en ànima, i és pròxim l'inconegut» («Sendes, camins em criden», v. 7-9)? Serà perquè, definitivament "[...] ja no sé la parla / dels homes, car he pres un sol camí, / el sempre inconegut vers l'indicible» («Totes les sendes moren», v. 7-9)? Serà la veu que pels mots «[...] es transfigura / l'inconegut en presència» («Aturo la imatge pura», v. 7-8)? La veu es resolt en càntic i en silenci.

REVISTA VALENCIANA DE FILOLOGIA / IV (2020) p. 223-250

JOAN REQUESENS I PIQUER

Jacob, la inspiració, Joan Vinyoli / 239 


\section{Dues realitats?}

Cal reconèixer que és del tot temptadora una lectura dualista d'aquesta poètica, i més a partir de «Nit d'àngel» i els «inconegut» i «misteri», «un déu», «indicible» deixats ara aquí ara allà. En el pròleg a El Callat, de totes totes, Vinyoli és clar. Ens diu amb plana llengua que fer ell mateix el pròleg suposa encarar-se amb el seu treball d'autor, trobar-se amb els seus versos «i intentant de veure quin sentit i quin valor tenen». Fet i fet, doncs, l'autor dels versos i el del pròleg cara a cara.

Però dialogar amb algú que en el fons sembla que viu la poesia més com un misteri quasi religiós o com un «exercici espiritual» que com un ofici, tot i que a ell mateix li dol de confessar-ho, perquè no vol ni pot desdenyar aquest aspecte del seu art, resulta complicat, desagradable i fatigós a la fi, si un estima l'objectivitat i la precisió tant com ell pugui estimar el secretisme i el misteri (Vinyoli 2001: 80)

Tot un paràgraf on la dificultat rau en com explicar el treball poètic exercit com un ofici ensems que un no poder amagar l'aparença que el poeta escriu des d'una creença de més enllà de l'ofici estricte que endemés no vol pas dissimular. Un poc més avall llegirem una referència a Raïssa Maritain que parla d'un coneixement saborós i obscur rebut en el recolliment com un do que cal merèixer, segons ella "font de la poesia i de tota intuïció creadora». Vinyoli hi diu seguidament: "Aquella activa recerca del poema era el contrari de la "inspiració" en el sentit d'illluminació o entusiasme; era, però, la possibilitat d'aplicar a la poesia una tècnica de "treball”". Amb pocs mots: reducció al treball poètic i tota concentració o contemplació com a tècnica del mateix treball. Per què?

[...] quan l'home es lliura, viu de retop la seva pròpia interioritat. La viu, no egoísticament, no amb avar afany de minaire que vol extreure qui sap quina riquesa dels pregons «replecs de la foscor del cor», sinó sorprès, innocent, meravellat de sentir-se amb ànima, de tocar unes profunditats

REVISTA VALENCIANA DE FILOLOGIA / IV (2020) p. 223-250

JOAN REQUESENS I PIQUER

Jacob, la inspiració, Joan Vinyoli / 240 
de l'ésser que present ja infinites; d'ací la importància del descobriment.

Per ell es va, pot anar-se almenys, cap a una poesia "substancial”, cap a la poesia, tot curt (Vinyoli 2001: 81).

Un altre paràgraf, i d'aquest, copsant-ne el sentit de tots els mots, els centro en tres paraules, «sentir-se amb ànima». Dues realitats només explicatives d'una unitat, la de qui se sent com tothom home igual i ensems doblat de poeta, sentir-se de manera nova quan la seva ànima s'autopercep d'una manera diferent de qui no és poeta o artista o, goso afegir, filòsof, contemplatiu religiós o de la simple naturalesa. En una de les proses més denses de Vinyoli, Pel camí del mesos, llegim: «Jo i Psique, la meva ànima, caminem silenciosos...». ${ }^{10}$ És per aquesta mala exposició de les meves paraules que es poden entendre aquests versos en el sentit que el poeta té com a correlat objectiu de si mateix realitats externes que li certifiquen el «sentir-se amb ànima»:

Jo no sóc més que un arbre sóc en la terra del foc mort sóc l'únic arbre en aquell lloc isard sóc riu encès, fluint des de l'origen sóc la llavor d'un invisible cedre sóc una cleda en el serrat sóc el planell arran de l'espedat sóc esperança, moviment cap a la llum, veu que celebra i sóc un àmbit on el cant circula com una sang, on tot, a cada instant, és únic i perfet i perdurable. ${ }^{11}$

10 Vinyoli 2001: 492. Imita Carles Riba? Li ret un homenatge? Fa seus els versos i la idea ribiana?: «Dins de la tarda nua caminàvem plegats / jo i Psique, la meva ànima ...» (Estances. Primer llibre, 2, v. 1-2).

11 Corresponen a: 1. "Algú m’ha cridat», v. 1; 2. «Foc mort», v. 8; 3. "Veu del promontori», v. 6; 4. «El riu encès», v. 4; 5. «El riu de pedra», v. 25; 6. i 7. «Bon pensament del vespre», v. 1 i 3; 8. "Orfeu», v. 9-10; 9. «Les aigües», v. 12-14.

REVISTA VALENCIANA DE FILOLOGIA / IV (2020) p. 223-250

JOAN REQUESENS I PIQUER

Jacob, la inspiració, Joan Vinyoli / 24I 
Comentari? Dos amb més versos:

[...] destrava

la llengua del mut;

brollin paraules de lloança

d'aquesta boca feta per al cant;

que simplement digui les coses,

una per una, les intactes,

virginalment ofertes:

muntanya, silenci, poma.

(«Àcida fruita», v. 8-15)

el primer; el segon

Dixaré flames i sostre

per anar cap al teu rostre,

perillosa summitat.

Ajudeu-me, flames mortes, vent gelat $\mathrm{i}$ closes portes, a obrir-me de bat a bat.

(«Simple cant a totes hores», v. 19-24)

No m'allunyo del «sentir-se amb ànima». Ara redueixo les tres paraules a una sola com ho fa el mateix Vinyoli: «descobriment». Haver-se sentit amb ànima ha estat una experiència $\mathrm{i}$ «inherent a l'experiència ha estat el "descobriment" actiu i allò que de commoció intel-lectualment $\mathrm{i}$ instintivament passiva comporta el "descobriment" (Serrallonga !983: 58). Aquests paraules de Segimon Serrallonga fan referència a El Callat i són tretes d'un comentari a dos llibres posteriors.

\section{La inspiració}

El llenguatge del poema em sembla lligat per dues bandes i ens cal desfer-ne el nus. Per l'una, la seva sintaxi. Per l'altra, la lectura o lectures que possibilita.

REVISTA VALENCIANA DE FILOLOGIA / IV (2020) p. 223-250

JOAN REQUESENS I PIQUER

Jacob, la inspiració, Joan Vinyoli / 242 
Es tracta, evidentment, d'unes estructures sintàctiques que combinen el conjunt de paraules les quals, amb la seva significació, generen la significació més àmplia de cada estructura. Intentaré de no perdre'm-hi. Qui parla en el poema, el poeta, ens diu «He lluitat amb un àngel», molt simplement. Es dona per entès qui és el poeta i se'ns diu qui és l'altre participant en la lluita, un àngel «vingut a mi», això és: també es dona per entès qui és un àngel i n’hi ha prou sabent que ha vingut. A continuació el motiu: «perquè [el poeta] participés d'allò més alt que salva", sense que igualment se'ns expliqui què sigui «allò» ni què cal entendre per "salvació». Entremig de les informacions de les dues oracions hi ha uns pocs aclariments. Sobre l'àngel tres observacions: és d' «inusitat ardor» ('qualitat d'ardent' i sinònims com ardència, xardor, etc. i figurativament vehemència, passió, etc.), "gran i fort»; ell, el poeta, és «temerari» ('que s'exposa i llança als perills sense reflexionar'). La primera estrofa o conjunt dels cinc primers versos presenta dos personatges en acció un dels quals, el que ha vingut impensadament, sota la imatge de la suposició o bé d'un imaginar-se que hom sabrà exactament qui és; l'altre, un poeta que és temerari. Un àngel? Deixant al pas allò que ens pugui suggerir un «se non è vero, è ben trobato», copio:

D'autres voient dans les anges des symboles des fonctions divines, des symboles des relations de Dieu avec les créatures; ou, au contraire -mais les opposés coïncident en symbolique-, des symboles de fonctions humaines sublimées ou aspirations insatisfaites et impossibles. Pour Rilke, de façon plus large encore, l'ange symbolise la créature dans laquelle apparait déjà réalisée la transformation du visible en invisible que nous accomplissons (Chevalier - Gheerbrant 1982: s.v. anges).

Els autors d'aquesta referència rilkiana no remeten d'on l'han treta, però diria que no és pas una afirmació desencaminada... No fou Rilke el far que il·luminà ben aviat el mester poètic de Vinyoli, per ell mateix confessat al Pròleg d'El Callat?:

[...] l'autor va triar un exemple de poeta que justament l'atreia pel que tenia de "quiet", de pacient, que ho esperava tot d'una lenta maduració,

REVISTA VALENCIANA DE FILOLOGIA / IV (2020) p. 223-250 JOAN REQUESENS I PIQUER

Jacob, la inspiració, Joan Vinyoli / 243 
que sobretot imposava per l'extrema capacitat d'“Erlebnis" que tenia i per la gran fidelitat amb què vivia la seva vocació (Vinyoli 2001: 80-81).

Erlebnis»: vivència o experiència interior o profunda. «Inherent a l'experiència és el “descobriment actiu” i allò que de commoció intel·lectual i instintivament passiva comporta el "descobriment" (Serrallonga 1083: 58).

Llegir aquesta estructura dels primers versos implica tot d'una interpretar-la des d'una visió cristiana o religiosa, camí barrat per les paraules del mateix Vinyoli, o bé per la banda de les significacions figuratives dels mots, començant per la de l'àngel i les qualitats a ell atribuïdes. L'àngel que se li presenta al poeta és simbòlic. Ara bé, ell, el poeta temerari, també? O són a la vegada possibles uns personatges de faisó diferent conjuntats en una significació superior? Potser només cal entendre que la lluita i la temeritat no es relacionen amb una acció física, sinó psíquica. Si fos així, l'àngel i el poeta es troben en un mateix pla. Aquest, en el del seu interior i aquell com a símbol d'allò que cal acomplir; o dit així: la transformació del treball poètic visible en l'invisible que acompleix, que duu a terme. Un treball en què «la poesia és sempre simbòlica, fins quan el poeta s'expressa en una forma directa» (Vinyoli 29001: 83). Més net i clar, impossible. Què o quin no visible? Esperem un poc.

La segona estrofa o bloc d'altres cinc versos. El poeta conta què li succeí en la lluita. En una primera aproximació ens diu: "Tens entre les seves mans debatent-me» (en un estricte ordre no retòric potser diríem "debatent-me tens entre les seves mans") i amb l'estat anímic següent, «amb meravella i espant». En una segona aproximació ens comunica què li succeí en aquesta situació a través d'una pregunta que ell mateix es fa perquè no sap pas copsar-ne l'abast ni el sentit: «quin misteri naixia en mi» que, de més a més «m’igualava», a qui? A l'àngel? Hom diria que sí, puix que el fet d'igualar-se amb ell, al capdavall, el sobrepassa — «sobrepassant-me»— com a ésser diferent, o com a pur símbol (menys que cosa del món usada com a símbol). Com en l'estrofa primera, hi ha en aquesta dos sintagmes d'enriquiment significatiu casualment molt iguals

REVISTA VALENCIANA DE FILOLOGIA / IV (2020) p. 223-250

JOAN REQUESENS I PIQUER

Jacob, la inspiració, Joan Vinyoli / 244 
que s'han d'interpretar: «com la nit», «com a la nit». Una comparació, de la qual n'és el segon terme i el primer ho és «tens», una situació muscular, la de significació recta, i psíquica, la figurativa en què es trobava el poeta durant la lluita. «Tens com la nit». Significa «tens» el que podem associar d'alguna manera amb la 'rigidesa', amb la 'pressió', amb la 'resistència', amb 'l'esforç continuat de l'esperit', assenyala també el diccionari normatiu. La nit, així, d'entrada, és el temps de la foscor i del silenci, resistència a la llum i als sons, pressió de la son i resistència a no adormir-se, esforç per restar en vetlla, temps, per tant, de reflexió en la solitud d'imatges visibles i audibles. En aquesta situació, evidentment més psíquica que simplement corporal, s'acreix el sentit de la meravella i de l'espant, dos pols oposats a l'hora d'assumir en la solitud un fet imprevist, una lluita que arriba i no es deixa de banda. La comparació es repeteix, la segona vegada, amb un altre primer terme. Cal observar que la primera vegada «la nit» és només un nom determinat i reduible, sembla, a una realitat genèrica, mentre que la segona, precedida de la preposició a accentua la duració del temps que hi duu associat (com la resta dels noms del concepte temporalitat: dia, setmana, mes, etc.), la referència més clara, diria, al relat bíblic on és present per la temporalitat, la durada de la lluita. És a dir, el poeta es troba igualat o semblant a la nit per la duració temporal, pel pas d'un temps, una successió, no una imatge només conceptual i, així, se li confirma que la lluita amb l'estat psíquic en què l'ha mantinguda, no és il-lusió d'un simple pensament, sinó l'acció anímica real, subjecta al temps, i ens ho transmet amb la preposició que diferencia els dos segons termes de la comparació.

La tercera estrofa, els últims cinc versos, no es mouen d'una descripció que exposa la veu poètica amb estructures sintàctiques també sobreposades. En la primera oració l'àngel com a subjecte d'una acció: «ell em cedia part del seu foc»; la segona, referida a ell mateix: «jo veia l'escala de la llum». La resta és tot això: en quina situació es troba el poeta després d'una nit —d'un temps indefinit, però no pas instant il·lusori- d'un llarg esforç? Una resposta clara i curta: «Quasi vençut». En aquest punt temporal, en aquesta hora final de perllongada tensió entre l'àngel i ell, aquell li ha fet do del foc que porta o de què és constituït, l' "ardor» anunciat en el segon vers. Foc que no ens priva

REVISTA VALENCIANA DE FILOLOGIA / IV (2020) p. $223-250$ JOAN REQUESENS I PIQUER Jacob, la inspiració, Joan Vinyoli / 245 
pas de pensar en una de les jerarquies angèliques de la tradició, la dels serafins, nom que literalment significa 'ardents', 'roents', 'abrasadors'. El poeta se sent posseïdor d'una ardència, d'un foc que no l'ha triat voluntàriament, se'l troba en ell donat... o descobert (paraula clau, com veurem i ja es percep un poc). $\mathrm{Ha}$ adquirit consciència d'una transformació en la seva interioritat fonda. El poeta, sembla que en concomitància amb la nova situació, veié «l'escala de la llum». Comprengué. Som sempre en un món figuratiu, simbòlic. La llum en la significació de coneixement. I els cants, les artesanies del treball lingüístic i semàntic del poeta baixaven per aquesta escala. Ho feien a la solitud, davallen «al cor solitari». Les obres del poeta seran cants, seran la seva veu més veritable, serà poeta, totalment. Assolirà «déjà réalisée la transformation du visible en invisible que nous accomplissons", ja realitzada la transformació del visible en l'invisible que acomplia. Les coses, la vida convertida en cants?

I seguiré el camí que les paraules apareixent em fressen, cap a quines profunditats? ...

... Oh veritable càntic!

( Seguiré el camí de les paraules», v. 1-3 i 8)

I «fressen»: fan el camí transitable per a mi.

Errant a la ventura

pel vespre sinuós, entre el foc i les ombres, he posseït el cant.

(«Errant a la ventura», v. 1-4)

Diria que no cal remarcar la proximitat del «vespre» amb la «nit», ni la presència del «foc» i de les «ombres» que fan pensar en la comprensió clara o no d'allò trobat «a la ventura», d'una pacient espera, és clar, com la recordada de Rilke. Comentari que, afegint-hi la consciència de passivitat, 'd'haver rebut', s'adapta i s'acreix pels versos següents:

REVISTA VALENCIANA DE FILOLOGIA / IV (2020) p. 223-250

JOAN REQUESENS I PIQUER

Jacob, la inspiració, Joan Vinyoli / 246 
Dominaré somnis de vent, pors de la nit, ones de febre, $\mathrm{amb}$ aquest do: càntic vivent?

(«Orfeu», v. 5-7).

Fins allò que és pur instant:

flor de neu, alba, rosada, duren sempre en el meu cant.

( Aturo la imatge pura», v. 12-14).

No són exactament, aquest versos, un exemple transparent de la transformació del visible en invisible ja realitzada? Coses fetes símbols, sempre, ens ha dit l'autor, Vinyoli, com ho rediuen més versos:

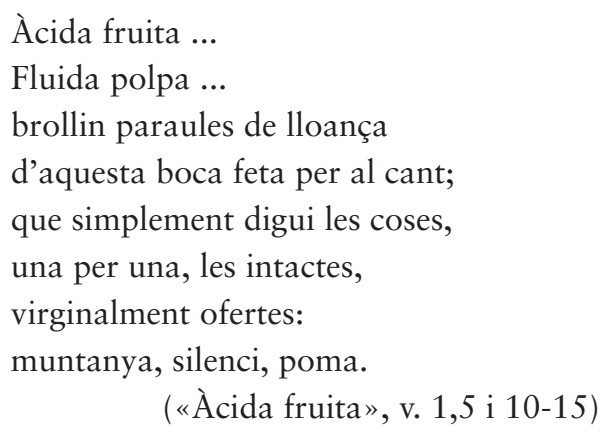

I amb més claredat, potser, els següents, amb veu segura:

És ara quan afirmo, coses, que sou, mentre m'estic bevent aquestes aigües de silenci que brollen de vosaltres, i sóc un àmbit on el cant circula com una sang, on tot, a cada instant, és únic i perfet i perdurable.

( «Les aigües», v. 8-14)

REVISTA VALENCIANA DE FILOLOGIA / IV (2020) p. 223-250 JOAN REQUESENS I PIQUER Jacob, la inspiració, Joan Vinyoli / 247 
Per deixar-ho confirmat definitivament amb igual seguretat de veu:

No puc abandonar-me com un quiet crepuscle daurat, sobre les coses, damunt allò que estimo.

Tothora en un batec impetuós, elevo la solitud a càntic.

(«El convit», v. 15-21).

Podríem tal volta asserir que el poeta s'ha reduït a ser això, el xuclador de les coses assimilades fins al punt de convertir-les en un cant en constant moviment, com la sang, en un batec constant, «és únic i perfet i perdurable» talment constant és la imatge de l'àngel com a símbol de la criatura que ha assolit allò que en ella s'ha d'acomplir. Per què? Perquè «Algú m'ha cridat». Aquest és el títol del primer poema del llibre El Callat, el qui fa i es perfà en el silenci:

«[...] bec solitud.

És per això que vago sempre

sota el silenci de les constelllacions

d'aquestes altes nits de fabulosa riquesa. (v. 6-9)

[...] M'endinso per un canvi

de les coses en ànima, $i$ és pròxim

l'inconegut.

(«Sendes, camins em criden», v. 7-9)

Així avança el poeta i dirà que:

mot per mot, es transfigura

l'inconegut en presència («Aturo la imatge pura», v. 7-8)

REVISTA VALENCIANA DE FILOLOGIA / IV (2020) p. 223-250

JOAN REQUESENS I PIQUER

Jacob, la inspiració, Joan Vinyoli / 248 
I tanmateix una presència que és enllà de les paraules

[...] Que ja no sé la parla

dels homes, car he pres un sol camí,

el sempre inconegut vers l'indicible.

(«Totes les sendes moren», v. 7-9)

I perquè «Paraules són misteri»

(«Un amb les coses», v. 11)

Vers a vers, fet i fet, el poeta «va sentir com la poesia demana llibertat, disponibilitat i risc, i que sols per aquí "s'obre a tot sense recel", és possible que un dia es facin entenedores - qui sap! - unes paraules senzilles, secretes, necessàries, plenes de sentit i de misteri» (Vinyoli 2001: 81). Exactament això: totes i cadascuna en el cant simbòlic... de què, de qui? Tal volta d'un mateix i el món circumdant, molt al propi fons, i en l'espirall fet versos que al lector, si els paladeja, tal volta li davallin al fons. L'àngel d'ardor i de flama el poeta se'l descobreix endins, ens ho diu en cada poema i potser l'àngel del lector en copsarà el senti i el misteri. Es comprèn? M'entenc? M'ho copsa el lector? Seran els de més verídica i clara significació, sense símbol ni secrets, els que es comprenen perquè comprenguem, s'entendran perquè m'entengui, aquests?:

Després de molta lluita, sols després, pot la mirada omplir-se i retenir calladament. I el gra madura als camps.

(«Diumenge», v. 16-18)

Qui pot dir, pagès o biòleg, vianant vora el camp o savi com madura el gra colgat a terra? Hi ha un darrer perquè sense resposta. En tot hom, també.

Potser la inspiració no és res més que tota aquesta volta, un camí que va de la veu a les coses, de les coses a «sentir-se amb ànima». Un senzillíssim anar pel món de les criatures i tornar al born d'un mateix, al clos on neixen i moren

REVISTA VALENCIANA DE FILOLOGIA / IV (2020) p. $223-250$

JOAN REQUESENS I PIQUER

Jacob, la inspiració, Joan Vinyoli / 249 
tots els combats, on "no hi ha fast més dolç que ésse' i gustar-se un mateix» ${ }^{12} \mathrm{i}$ descobrir, els qui de fora estant llegim tota l'aventura poètica, que, pel correlat bíblic del patriarca Jacob s'ha fet realitat el judici de Northrop Frye, «que la Bible présente aussi comme une forme de "révélation": la vision, le modèle, le plan qui donne une orientation aux énergies de l'homme» (Frye 1984: 201). Les de Joan Vinyoli, poeta, testimoniades a «Nit d'àngel» i en els altres poemes d'El Callat.

\section{Bibliografia}

CARbó, F. (1990) Joan Vinyoli: escriptura poètica i construcció imaginària, València/Montserrat, IFV/PAM.

Chevalier, J. - Gheerbrant, A. (1982) Dictionnaire des symboles, Paris, Robert Lafont. Ferrater G. (1971) «Prefaci» dins Carles Riba, Versions de Hölderlin. Barcelona, Edicions 62. Frye, N. (1984) Le Grand Code. La Bible et la littérature, Paris, Éditions de Seuil.

Garcilso de la Vega (1979) Poesías castellanas completas, Madrid, Castalia.

Obermayer, H. et alii (1979) Diccionario bíblico manual (Edición ecuménica). Barcelona, Claret.

Pinell i Pons, J. (1986) «L'esfera del diví en la poesia de Carles Riba», Actes del simposi Carles Riba. Institut d'Estudis Catalans, 17-19 d'octubre de 1984, Montserrat, PAM.

Serrallonga, S. (1983) «Del Llibre d'Amic als Cants d'Abelone», Reduccions. Revista de poesia, núm. 20, pp. 57-63.

VInYoli, J. (2001) Obra poètica completa, Barcelona, Edicions 62.

12 Vers 16 de l'elegia IX de Carles Riba i la resta de significació d'aquest poema.

REVISTA VALENCIANA DE FILOLOGIA / IV (2020) p. 223-250

JOAN REQUESENS I PIQUER

Jacob, la inspiració, Joan Vinyoli / 250 